\title{
Irrigated Agriculture on Saline Soils: A Perspective
}

\author{
Anna Tedeschi (D) \\ National Research Council of Italy, Institute of Biosciences and Bioresources, Research Division Portici, \\ Via Università 133, 80055 Portici, Italy; Anna.Tedeschi@cnr.it; Tel.: +39-081-2539585
}

Received: 4 October 2020; Accepted: 20 October 2020; Published: 23 October 2020

Abstract: Approximately $6.5 \%$ of the world's arable and marginal soils are either saline or sodic. The situation will worsen due to climate change. Regardless of the cause that generated the salinity, i.e., whether primary or secondary, the effect of soil salinization on plant growth and on living organisms will be severe. To mitigate such impacts, several studies have been carried out over the years with the aim of providing technical or management solutions to deal with the multiple consequences of soil salinity. A review by Cuevas et al. proposes a new approach looking for solutions through soil-improving cropping systems (SICSs). The SICSs have to prevent, mitigate or remediate the negative impacts of soil salinization. The efforts of Cuevas et al. were to organize the analyses by focusing on SICSs that would: (1) prevent or halt secondary salinization; (2) cope with salinization; (3) reverse salinization. The study is concluded by an effort to assess the impacts of each SICS and of the combined SICSs application in terms of agronomic, economic, and environmental aspects. Both economic constraints and the collective willingness of stakeholders to innovate are taken into in the evaluation of feasibility. It is important to put into practice and/or identify a number of sustainable actions, at low environmental input, to improve crop tolerance to water deficit and high salinity as well as to preserve biodiversity and mitigate the impact of climate changes. At the same time, these actions would ensure crop productivity in the area, thus guaranteeing environment and social benefits to the local population, and thus weakening the motivation to abandon the land. The aim of this editorial is to propose a broader perspective on the review by Cuevas et al. "A Review of Soil-Improving Cropping Systems for Soil Salinization". In the review, the authors go through several soil-improving cropping systems (SICSs) by considering them separately or in combination with the aim to provide guidelines towards resolving, counteracting or mitigating soil salinity. I tried to highlight the strengths of the study by Cuevas et al., while suggesting related topics that may deserve further attention by the community.

Keywords: soil salinity; soil structure; soil physical properties; irrigation management; saline water; crop yield; yield quality; soil mulching; rhizosphere microorganisms

\section{Agriculture and Saline Soils}

The aim of this editorial is to propose a broader perspective on the review by Cuevas et al. [1], "A Review of Soil-Improving Cropping Systems for Soil Salinization". In the review, the authors go through several soil-improving cropping systems (SICSs) by considering them separately or in combination with the aim to provide guidelines towards resolving, counteracting or mitigating soil salinity.

I tried to highlight the strengths of the study by Cuevas et al., while suggesting related topics that may deserve further attention by the community.

Litalien and Zeeb [2] report that from soil surveys conducted in the 1970s and 1980s, the Food and Agriculture Organization of the United Nations (FAO) estimated that approximately $6.5 \%$ of the world's arable and marginal soils were either saline or sodic (FAO, [3]). In a recent study, Daneshmand et al. [4] 
underline that the expansion rate of dryland salinization worldwide is expected to increase due to climate change mainly because of the expansion of drylands.

Soils become saline due to the deposition of salt either by natural (primary) or anthropogenic (secondary) processes. Evelin et al. [5] summarized that primary processes include the weathering of parent rocks, deposition from sea water and atmospheric deposition. Secondary processes include poor drainage facilities, irrigation with brackish groundwater, continuous irrigation for long durations, improper management of water, and cultural methods in irrigated agriculture.

In any case, soil salinization is an ecological disaster that causes the degradation of soil quality, especially in arid and semi-arid areas [6], which has repercussions on crop productivity and consequently an economic issues in the world. This scenario is already complex to manage and is further aggravated by the effect of climate change, which will lead to the generation of new saline areas and perhaps ameliorate salinity in some already saline areas. In fact, according to Schofield and Kirkby [7], an increase in evaporation will increase the amount of salts drawn to the soil surface, increasing salinization, whereas periodic leaching during high-intensity rainfalls, with less standing vegetation, can desalinize soils at well-drained sites or increase salinization in high groundwater areas. It is less well known how climate change will affect the spatial distribution of salt-affected soils.

In terms of environmental stresses, saline stress, regardless of whether caused by saline soil or irrigation with saline waters, is considered the most severe stress that affects not only the soil properties and plant growth but also the living organisms. The effects of salinity on plants include ion toxicity, osmotic stress, impaired growth, mineral deficiencies, photosynthetic imbalance, and combinations of these effects.

To counteract the effects due to salinity, several studies have been carried out over the years with the aim of providing technical or management solutions to counter, reduce, and mitigate salinity. Many of them gave useful results; others, with the worsening of aridity conditions also due to climate change, have become difficult to apply in some areas-for example, leaching with good quality water, which is no longer available in some territories.

The review by Cuevas et al. proposes a new approach through a meta-analysis, to articulate an interesting synthesis on possible, known or new cropping systems. The review looks for solutions through a single or multiple soil-improving cropping systems (SICSs). The SICSs are designed to prevent, mitigate or remediate the negative impacts of soil salinization by ameliorating the associated soil and ecosystem services.

They divided the approach into three types: (1) preventing or halting secondary salinization; (2) coping with salinization; (3) reversing salinization.

\section{Prevent Salinity}

Regarding preventing or halting secondary salinization, they analyzed leaching, drainage and water table management as water management solutions. Considering this section and the different practices described that are certainly useful for preventing or controlling salinity, attention must be paid also to a few other aspects. Territories affected by salinity are often not economically developed areas and therefore the farmers have few financial resources to make investments in drainage systems or other interventions that help drain the salts and prevent an increase in groundwater salinity. The other consideration is that leaching is feasible, if good quality water is available. In many salt-affected areas, fluctuations in available fresh water are due to weather variability (drought spells) and climate trends. That is, wet years refill water reservoirs and dry years reduce the availability of the good quality water needed for pre-sowing leaching and/or during the crop cycle. Climate change in this context has exacerbated, in some areas, the reduction in good quality water due to the persistence of dry years. On the other hand, even a good quantity of autumn-spring rains (e.g., $800 \mathrm{~mm}$ ) may not be sufficient to leach the salts from the soil profile. Leaching can occur in the root zone, but with the new irrigation season salinity may increase again due to salt upward transport by capillary rise and by application of saline irrigation water (see [8], for further details). 
Cuevas et al. mention leaching by rainfall, but the role of soil properties should be taken into account. For example, leaching of clay soils is hampered by the low permeability, which adds to the constraints on proper root development and functioning. Moreover, in saline soils a saline crust is often deposited on the soil surface, which reduces infiltration and may lead to water ponding.

Regarding option (2), i.e., coping with salinization, Cuevas et al. include in this section: irrigation management, nutrient management, soil management, crop rotation, salinity tolerant crops and rootstocks.

\section{Cope with Salinity}

A lot of knowledge and information has been acquired during the years. In several countries, this information has also been made available to farmers to help them to deal with salinity. Despite this, the fact remains that farmers tend to irrigate with the aim of replenishing consumptive water use assumed to be equal to full crop water requirements. Farmers tend to believe that more water will increase crop production. This is true up to a point where yield reaches its maximum value and additional amounts of irrigation do not increase it any further. Therefore, it can be easily understood how difficult it is to introduce and apply deficit irrigation approaches. Certainly, as stated by Cuevas et al., the price of water could be an incentive to save water. On the other hand, in some countries affected by salinity, water is not available on demand. Both timing and amount of irrigations are constrained by the water management system, including water quality, regardless of farmers' expectations.

The application of a SICS, where soil is deeply involved such as in leaching, drainage and irrigation, requires a broad and deep knowledge of the soil responses to these practices. Saline water modifies soil physical properties-e.g., soil structure and total porosity. These changes modify the hydraulic conductivity, thus affecting water movement and soil water retention. Basile et al. [9] document in detail the changes in soils' physical properties under application of saline irrigation water in a soil with high clay content. In Huang et al.'s work [10] similar results were reported on a silty loam soil. In both studies, a soil affected by salinity underwent a reduction in total porosity with a loss of larger pores and an increase in smaller pores.

The modification of the soil physical properties plays a crucial role in soil management under irrigation and in general in the hydrological soil behavior (drainage, leaching). Tedeschi et al. [11] reported results on modified soil physical properties and the consequences in irrigation management. Saline water tends to modify soil water retention in such a way that saline soils tend to retain more water than non-saline soils. This implies different timing and amounts of irrigation for the two soils. To deal with this situation, a suitable irrigation schedule can be designed by taking into account expected soil water content, crop sensitivity and available irrigation water to avoid the increase in osmotic potential-i.e., salinity stress.

Over the years, the scientific community has developed and applied numerical models of solute and water flow in soils to evaluate crop and water management options. They can be used to evaluate the consequences of changes in plant and soil properties or irrigation strategies, and thus provide a more concrete basis to assist agronomists, breeders, farmers and supporting services. In Tedeschi and Menenti's work [12], an evaluation of different irrigation strategies was carried out on a saline soil to determine the sustainability of long-term irrigation by different strategies and taking the expected evolution of the hydrological conditions.

Cuevas et al. introduce soil mulching as a soil management technique, which is applied to reduce soil evaporation-i.e., salt concentration and deposition in the root-zone and the water volume applied by irrigation. Soil mulching is already applied in some arid-saline lands such as in the Northwest of China. This is carried out with Poly-vinyl chloride (PVC) plastic film. As reported by Ingman et al. [13], the amount of film used is huge and disposal of such material after use is not environmentally sustainable. The film after use is not recycled but is burned or buried in the ground. The Chinese case must make us think that although mulching should be promoted to contrast salinity, it must be eco-friendly. An eco-friendly method is the straw mulching described by Cuevas et al., 
but should also include some new generation biodegradable mulching spray. The latter has the advantage that it can be sprayed on the soil and is decomposed with time in the soil, as reported by Giaccone et al. [14], and the additional environmental advantage that is produced mostly with waste residue.

Some remarks in Cuevas et al. on crop rotation and the selection of salinity-tolerant species and varieties deserve to be considered. Extreme and prolonged saline stresses can determine a reduction in production. In some case the yield reduction is partly offset by an improvement in produce quality. For example, in melon there is an improvement in the total soluble solid (TSS) content of the fruits [15], as well as the shelf life [16] which are two positive perspectives compared to lower yield. This quality improvement, thus higher market value, might be particularly relevant in poorer areas.

Regarding the tolerance of plants to salinity, the point of view should be changed a little. For several years, and still today, the relationship found by Maas and Hoffman [17] (M\&H) relates relative crop yield to soil salinity. One use of the relationship is to select plant and varieties that are tolerant under salinity conditions. The relationship was estimated under saturated soil conditions; therefore, this information needs to be kept in mind when applying such relationships to assessments under open-field conditions.

In a saline soil, which is generally combined with soil limited water availability, the conditions, i.e., at saturation, where the classification of $\mathrm{M} \& \mathrm{H}$ applies almost never occurs or only for very limited periods of time. Therefore, if, for a given plant, the threshold value according to M\&H is known, this threshold value should be corrected by taking into account the real water content of the soil (see [18], for further details).

The last sections of Cuevas et al. are interesting for the evaluation of the simultaneous application of multiple agronomic solutions and for the promotion of biotechnologies to obtain salinity-tolerant plants. The assessment of the SICSs application, in terms of agronomic, economic, and environmental aspects is summarized in Figure 3 in Cuevas et al.

\section{Perspective}

Although not mentioned by Cuevas et al., the potential beneficial action of soil microorganisms on plant performance under stress condition should be mentioned. The rhizosphere is rich in bacteria and fungi capable of overcoming the detrimental effects and ameliorating plant performance under environmental stress. The identification of highly efficient microorganisms (e.g., native Arbuscolar Mychorriza Fungi (AMF), and Plant growth-promoting bacteria (PGPB) from unfavorable environments) is expected to improve their practical exploitation in soil and crop management. This technique has the potential to help farmers to improve plant health and productivity under sub-optimal stressed conditions. This topic attracted a strong interest of the agro-industry for the development and commercialization of products that come out from the selection of AMF or PGPB. Most of the positive results have been obtained under strictly controlled environmental conditions; thus, open-field trials are needed to evaluate reliability to respond on a larger scale use to salinity conditions. A promising indication is the selection of AMF and PGPB from the rhizosphere of native plant that already live in a saline and arid environment. Some examples are described in Lumini et al. [19].

\section{Conclusions}

The study by Cuevas et al. [1] helps to unravel the wide range of studies and results on salinity remediation by crop management, particularly by applying both one solution at a time or combination of multiple solutions. As Cuevas et al. critically state, the crucial point is to hope that farmers will be willing to adopt the innovative strategies.

In this regard, I believe that uptake of innovations by farmers will depend on providing sufficient evidence on the economic and social benefits. Such evidence will generate consensus towards investing resources and efforts to innovate farming practices. As already mentioned during the analysis carried out so far, many of the areas affected by salinity are also economically less developed and therefore 
with limited resources to invest in innovations. This criticality goes together with the poor ability to deal collectively with this problem and to share innovative solutions within the stakeholder community. Another challenge is that benefits of innovations in crops, irrigation management and soil management typically appear on a longer timescale, thus making efforts in this direction less rewarding because the benefits are not immediately tangible. I believe that if this reality is not changed, by strongly promoting international exchanges on "success stories", e.g., in the USA and Australia, it will be difficult to see real progress. Hoping that such a vision will begin as soon as possible, it is equally important to train stakeholders with technical scientific knowledge that allows them to know how to manage their territory. As previously mentioned, everything starts from the soil and if its dynamics and behaviors are not understood, it will not be possible to implement the most appropriate SICS with the appropriate corrective actions linked to the specificity of the soil to be managed.

Funding: The work summarized in this review was supported by the bilateral cooperation program of the National Research Council CNR and Chinese Academy of Science CAS and by the Working Group Poor Quality Water (PQW) of the International Commission of Irrigation and Drainage (ICID).

Conflicts of Interest: The author declares no conflict of interest.

\section{References}

1. Cuevas, J.; Daliakopoulos, I.N.; del Moral, F.; Hueso, J.J.; Tsanis, I.K. A Review of Soil-Improving Cropping Systems for Soil Salinization. Agronomy 2019, 9, 295. [CrossRef]

2. Litalien, A.; Zeeb, B. Curing the earth: A review of anthropogenic soil salinization and plant-based strategies for sustainable mitigation. Sci. Total Environ. 2020, 698, 134235. [CrossRef] [PubMed]

3. FAO. Saline Soils and Their Management. Food and Agriculture Organization of the United Nations. 2016. Available online: http://www.fao.org/3/x5871e/x5871e04.htm (accessed on 15 September 2020).

4. Daneshmand, H.; Alaghmand, S.; Camporese, M.; Talei, A.; Yeh, P.J.-F.; Daly, E. Long-term impacts of partial afforestation on water and salt dynamics of an intermittent catchment under climate change. Water 2020, 12, 1067. [CrossRef]

5. Evelin, H.; Devi, T.S.; Gupta, S.; Kapoor, R. Mitigation of salinity stress in plants by arbuscular mycorrhizal symbiosis: Current understanding and new challenges. Front. Plant Sci. 2019, 10, 470. [CrossRef] [PubMed]

6. Zhang, H.; Pang, H.; Zhao, Y.; Lu, C.; Liu, N.; Zhang, X.; Li, Y. Water and salt exchange flux and mechanism in a dry saline soil amended with buried straw of varying thicknesses. Geoderma 2020, 365, 114213. [CrossRef]

7. Schofield, R.V.; Kirkby, M.J. Application of salinization indicators and initial development of potential global soil salinization scenario under climatic change. Glob. Biogeochem. Cycles 2003, 17, 1078. [CrossRef]

8. Tedeschi, A.; Dell'Aquila, R. Effects of irrigation with saline waters, at different concentrations, on soil physical and chemical characteristics. Agric. Water Manag. 2005, 77, 308-322. [CrossRef]

9. Basile, A.; Buttafuoco, G.; Mele, G.; Tedeschi, A. Complementary techniques to assess physical properties of a fine soil irrigated with saline water. Environ. Earth Sci. 2011, 66, 1797-1807. [CrossRef]

10. Huang, C.; Xue, X.; Wang, T.; De Mascellis, R.; Mele, G.; You, Q.; Peng, F.; Tedeschi, A. Effects of saline water irrigation on soil properties in northwest China. Environ. Earth Sci. 2010, 63, 701-708. [CrossRef]

11. Tedeschi, A.; Lavini, A.; Basile, A.; Mele, G.; Menenti, M. Highlights of an experimental study on the vulnerability of a soil-crop system to drought and saline water. In Proceedings of the Congress of the European Society of Agronomy-Multi-functional Agriculture-Agriculture as a Resource for Energy and Environmental Preservation, Bologna, Italy, 15-19 September 2008; Italian Journal of Agronomy. Volume 3 (Suppl. 3), pp. 165-166.

12. Tedeschi, A.; Menenti, M. Simulation studies of long-term saline water use: Model validation and evaluation of schedules. Agric. Water Manag. 2002, 54, 123-157. [CrossRef]

13. Ingman, M.; Santelmann, M.V.; Tilt, B. Agricultural water conservation in China: Plastic mulch and traditional irrigation. Ecosyst. Health Sustain. 2015, 1, 1-11. [CrossRef]

14. Giaccone, M.; Cirillo, C.; Scognamiglio, P.; Teobaldelli, M.; Mataffo, A.; Stinca, A.; Pannico, A.; Immirzi, B.; Santagata, G.; Malinconico, M.; et al. Biodegradable mulching spray for weed control in the cultivation of containerized ornamental shrubs. Chem. Biol. Technol. Agric. 2018, 5, 21. [CrossRef] 
15. Huang, C.H.; Zong, L.; Buonanno, M.; Xue, X.; Wang, T.; Tedeschi, A. Impact of saline water irrigation on yield and quality of melon (Cucumis melo cv Huanghemi) in northwest China. Eur. J. Agron. 2012, 43, 68-76. [CrossRef]

16. Tedeschi, A.; Lavini, A.; Riccardi, M.; Pulvento, C.; d'Andria, R. Melon crops (Cucumis melo L., cv. Tendral) grown in a Mediterranean environment under saline-sodic conditions: Part I: Yield and quality. Agric. Water Manage. 2011, 98, 1329-1338. [CrossRef]

17. Maas, E.V.; Hoffman, G.J. Crop salt tolerance. Current assessment. ASCE J. Irrig. Drain. Div. 1977, 103, 115-134.

18. Tedeschi, A.; Zong, L.; Huang, C.; Vitale, L.; Volpe, M.G.; Xue, X. Effect of salinity on growth parameters, soil water potential and ion composition in Cucumis melo cv. Huanghemi in North-Western China. J. Agron. Crop Sci. 2017, 203, 41-55. [CrossRef]

19. Lumini, E.; Pan, J.; Magurno, F.; Huang, C.; Bianciotto, V.; Xue, X.; Balestrini, R.; Tedeschi, A. Native arbuscular mycorrhizal fungi characterization from Saline Lands in Arid Oases, Northwest China. J. Fungi 2020, 6, 80. [CrossRef] [PubMed]

Publisher's Note: MDPI stays neutral with regard to jurisdictional claims in published maps and institutional affiliations.

(C) 2020 by the author. Licensee MDPI, Basel, Switzerland. This article is an open access article distributed under the terms and conditions of the Creative Commons Attribution (CC BY) license (http://creativecommons.org/licenses/by/4.0/). 